\title{
Modelling the Urban Interface by Using Fuzzy Logic
}

\author{
Havva Alkan-Bala1, Taner Üstüntaş ${ }^{2 *}$ \\ ${ }^{1}$ Department of Architecture, Faculty of Architecture, Selçuk University, Konya, Turkey \\ ${ }^{2}$ Department of Geodesy and Photogrammetry, Faculty of Engineering, Selçuk University, Konya, Turkey \\ Email: ${ }^{\text {halkanbala@gmail.com }}$
}

Received 29 December 2013; revised 7 February 2014; accepted 19 February 2014

Copyright (C) 2014 by authors and Scientific Research Publishing Inc.

This work is licensed under the Creative Commons Attribution International License (CC BY). http://creativecommons.org/licenses/by/4.0/

(c) (i) Open Access

\section{Abstract}

This paper discusses the validity of the urban interface dichotomy in the urban planning and scientific literature by means of a new approach and proposes a new model. Although the concept of "Urban Interface" (UI) is discussed widely in the context of urban-rural and/or natural-artificial environment, UI has been used in the computer and communication disciplines, as well as in economy, geography, regional planning, city planning and architecture. UI has also been used in relation to electronic traffic control systems in urban transportation. UI between buildings and city is a relatively new issue in the literature. UI is defined with variant paradigms since the phenomenon is uncertain. This article reports on the use of fuzzy logic to create a kind of expert system for evaluating architectural elements in the context of UI. Fuzzy is the mathematical models of verbal expression on the area of specialization. This study is useful because this study shows a way to transform non-intuitive and precise concepts to the measurable and accurate results into a model. In order to create a model, the definition of $\mathrm{UI}$ in literature is evaluated and according to this evaluation a definition in terms of architecture is determined. The model of this new definition is created with using fuzzy logic using the Fuzzy Tec software. The predictions and experiences of a designer are represented in the model, which has been designed to behave like an expert person. Therefore, it has been shown that the definition of "expert system" can be added to architectural software. Lastly, a model that can give a fuzzy logic system for determining the quality of Urban Interface with sixteen parameters has been presented to the scientific field.

\section{Keywords}

Expert System; Fuzzy Logic; Urban Interface; Urban Space

${ }^{*}$ Corresponding author. 


\section{Introduction}

Urban Interface (UI) has been analyzed in the context of urban-rural and natural-artificial environments and space-digital representation of space in the literature. UI has been used in the computer and communication disciplines, as well as in economy, geography, regional planning, city planning and architecture. UI has also been used in relation to electronic traffic control systems in urban transportation. References to UI occur in international fire regulations, in sources about fire prevention, in the terminology of "recycling energy technologies" that have recently arisen, as well as in sustainability and ecology. However, UI has not been deeply evaluated in the New Urbanism Movement [1]-[7] which has used UI as the interaction and transition of spaces between the city and buildings, with the aim of increasing environmental quality. This paper discusses the validity of the urban interface dichotomy in the urban planning and scientific literature by means of a new approach and proposes a new model.

The importance of this study is to create a model for urban space that has perceptual variation and indefiniteness by using, for the first time, the fuzzy logic method. This model is also important in its contribution to the scholarly arena as a structure for later scientific inter disciplinary studies on UI. Thus, the intuitive experiences have become anonymous sharing by means of this mathematical model. This model is an opportunity to decide if the produced urban interfaces are good enough or not in a way that it is independent from the intuitive experience of the designers. This study is useful because this study shows a way to transform non-intuitive and precise concepts to the measurable and accurate results into a model. Obtained with this approach could not be done as simple as statistical way. In this sense, that is the authenticity of the work.

\subsection{The Concept of UI in Literature}

UI has existed since people created organized settlements, but studying this phenomenon associated with spatial conditions is a relatively new occurrence. This growing interest of the concept in literature can be classified into four groups. The first group of studies about UI concerns those areas where urban settlements meet wild-lands [8]. Studies in this group examine wild-land area, their environmental problems and land use, especially their economic, social, political and legal aspects. Topics include ecosystem fragmentation, increased exposure to invasive species, water and air pollution, wildfires and loss of habitat for wildlife [9]-[12]. UI here is described as the area where urban areas meet and interact with rural lands [11] [13]. It also includes the edges of large cities and small communities, areas where homes and other structures are intermixed with forests, and other land uses and islands of undeveloped property within urban areas. In some studies, the concept of interface is used to highlight the role that urban design can play in mediating the bringing together of urban activities that have been isolated from one another [14]. In this way, UI is defined as the transition area between urban life and wild-land environment in a macro-scale [10] [11] [15]-[19]. Moore also refers to this group while explaining UI as a matrix of patches [20]. Davis [21] describes three types of interfaces: classic, intermix and isolated. Classic interface situations can be seen in many of the regional parks and forests where subdivisions and other development have grown to the very borders of the park or forest. In this sense, the interface has a clearly identified line of demarcation. In an intermix situation, developments (such as homes or other structures) are scattered throughout the wild-land area. This "shotgun" pattern of land ownership presents the resource manager with a particularly vexing set of management problems. In the isolated interface, wild-land areas are essentially surrounded by development. Prime examples of interface include urban and municipal parks and greenbelts. As argued by Bradley [22], Kelly [23] and extended by Ewerd [9], the interface can be considered as different patterns of a mix between developed and natural landscapes_-an area that managerially reflects advanced society values such as congestion; or an area that can be thought of as a natural resource or "ecotone".

The second group understands the concept of UI as a social issue. Conflicts associated with use patterns, resource allocations and goal attainment have become more intense and polarizing [11] [24] [25]. In general, boundaries divide and connect at the same time, marking the transition between different uses or territories. From this, it follows that urban boundaries can be defined as the change-over from the urban to the rural area; e.g. indicated through different land-uses that reach from high density commercial uses at the CBD to low density agricultural uses at the edge of the city including differences in their built-up density-villages that are connected to the urban area by some development may also be related to the city [26] [27]. The ownerships of new lands and new neighbourhoods bring new cultural occurrences due to urban migration. Many types of land 
ownerships in the interface bring "new neighbours" with different set of values, lifestyles and land ethics into the interface and, as a result, conflicts and tensions arise between these "new" and "existing" communities and cultures [7] [14] [28]-[31].

The third group regards hazards to life and property that have evolved over time as a result of urbanization and also other uses that have spread to the interface where fire and flood present serious and periodic threats. Scientific discussions about the increasing fire risk ratio in transitional areas where urban and forest ecosystems meet can be seen in literature [32]-[40].

The fourth group is spatial. In spatial terms, UI can be defined as the border, the transition, the edge, gap or volume between one environment and another [14]. According to Gehl [41], interface is the transitional area between private and public areas. Here, a definition of UI belonging to space and imaginary media is seen. According to Gorden [42], UI is the mediation between material city (building and city) and the city of images (representations and imagination). The interface, then, is the perpetual movement between these two poles. The New Urbanism movement debates UI, objecting to the loss of a sense of place in the urban environment [1]-[7] using UI as a part of planning activity for creating "good places" [1] [43]. In articles that concentrate on urban growth and its effects, UI is evaluated according to population, economy, infrastructure, services, land use and settlements [44].

In Turkey, there have been several studies where UI has been used spatially. Özaydin [45], has taken UI as "surfaces that are located in the interface of urban outer spaces in urban residential areas and composed of the total of architectural facades”. Özyörük [46], on the other hand, has explored UI as transitional zones. Köknar [47] has defined the same concepts as a result of the interaction of social life: the city where people are "free", "keep away from the stresses of daily life", and "meet" in the urban environment-where human activity takes place. In the current study, as Bala [48] has described, UI has horizontal and vertical components. Horizontal components consist of the positioning of buildings in relationship to one other, the design of the buildings and their spaces including the volumes between buildings. Vertical components are taken as flexible and fluent environments that are made up of architectural facades that delimit outer spaces. The type of UI mentioned in this article matches the above definitions.

\subsection{The Scope of Study}

This study discusses the phenomenon of UI that plays a role in the interaction and transition between architecture-urban planning, building-city, interior-exterior and private-public. UI terminology borrowed from the field of informatics is related to intermediate software that enables the use of the computer programs and software without explicitly knowing the software language. If architecture is interpreted as an interface that provides the relationship between user and the information that forms the structure, space becomes a kind of software. In this respect, there are interfaces between space and meaning, form and function, figure and ground, outdoor and indoor, city and building, wild life and urban life, and rural and urban areas. In this study, the UI phenomenon, which borrows from various disciplines, is examined in terms of its horizontal and vertical components (Figure 1).

\section{Method}

Fuzzy Logic (FL) is a form of manyvalued logic; it deals with reasoning that is approximate rather than fixed and exact. The definition of FL was first made by Zadeh [50] in 1965. FL systems find application especially in engineering systems due to their suitability for applications. However, the fuzzy concept is particularly valid also in the areas where information is qualitative. In contrast, the FL employment in soft sciences is not as straight forward as it is in exact sciences and special care should be taken in the former case. In this work, aspects of FL implementation in the areas of soft sciences are pointed out. This is exemplified by a design application in building technology using a soft design data set from a real life environment. Compared to traditional sets where variables may take on true or false values fuzzy logic variables may have a truth value that ranges in degree between 0 and 1 . Fuzzy logic has been extended to handle the concept of partial truth, where the truth value may range between completely true and completely false. An FL system can be defined by input sets, and the subsets of these sets, rule-based definitions and output sets (Figure 2).

We can explain the basic idea of FL with temperature measurement. Temperature ranges needed to control the 


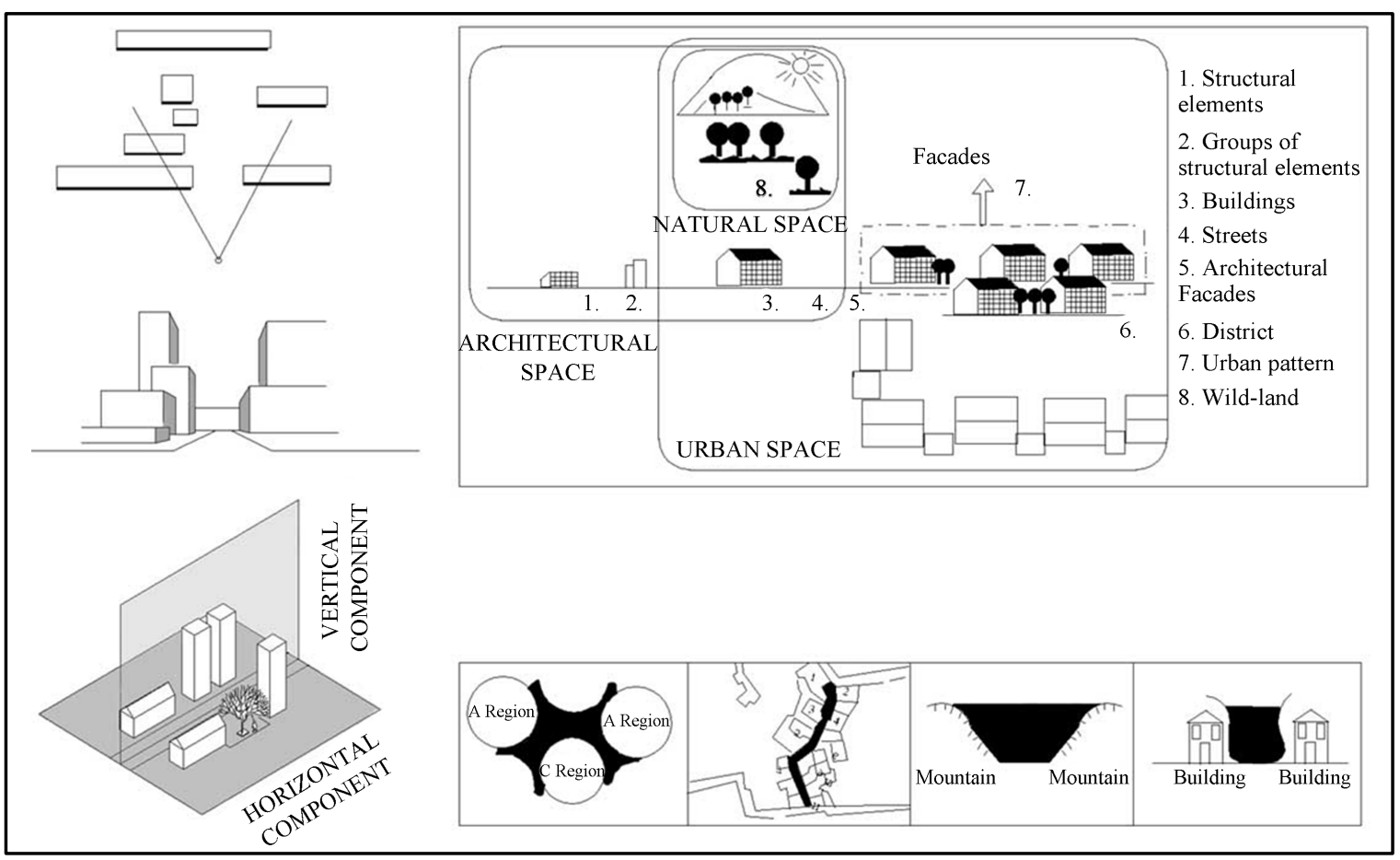

Figure 1. The schematic explanation of UI [(improved by the help of ([49] p. 15), ([45] p. 6-7) and ([48] p. 33)].

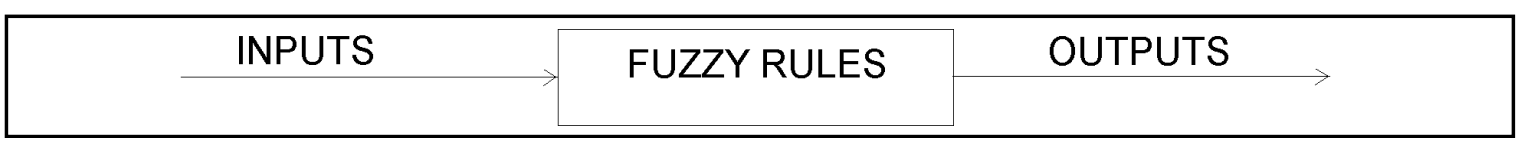

Figure 2. General fuzzy logic system.

barekes properly. Each function maps the same temperature value to a truth value in the 0 to 1 range. These truth values can then be used to determine how brakes should be controlled. In Figure 3, the meanings of the expressions cold, warm, and hot are represented by functions mapping a temperature scale. A point on that scale has three "truth values"- one for each of the three functions. The vertical line in the image represents a particular temperature that the three arrows (truth values) gauge. Since the red arrow points to zero, this temperature may be interpreted as "not hot". The orange arrow (pointing at 0.2) may describe it as "slightly warm" and the blue arrow (pointing at 0.8) "fairly cold”.

\section{Why Using Fuzzy Logic Is Useful for Illustrating UI}

In order to create a model, the definition of UI in literature is evaluated and according to this evaluation a definition in terms of architecture is determined. This study is useful because this study shows a way to transform non-intuitive and precise concepts to the measurable and accurate results into a model The model of this new definition is created with using fuzzy logic using the Fuzzy Tec software. The predictions and experiences of a designer are represented in the model, which has been designed to behave like an expert person. Therefore, it has been shown that the definition of "expert system" can be added to architectural software. The model that can give a fuzzy logic system for determining the quality of Urban Interface with sixteen parameters has been presented to the scientific field.

In this study, UI has been modelled with the fuzzy logic method. For UI to be easy and understandable in terms of fuzzy logic, the vertical and horizontal compounds are distinctly defined as fuzzy systems. These two compounds are then divided into two: horizontal viewing, horizontal sensing, vertical viewing, and vertical sensing. All viewing and sensing fuzzy logic identifications are a system with four inputs and one output. The identification of UI has been made with a fuzzy system with horizontal and vertical compounds. In FL, the inputs must be blurred as in Figure 4. 


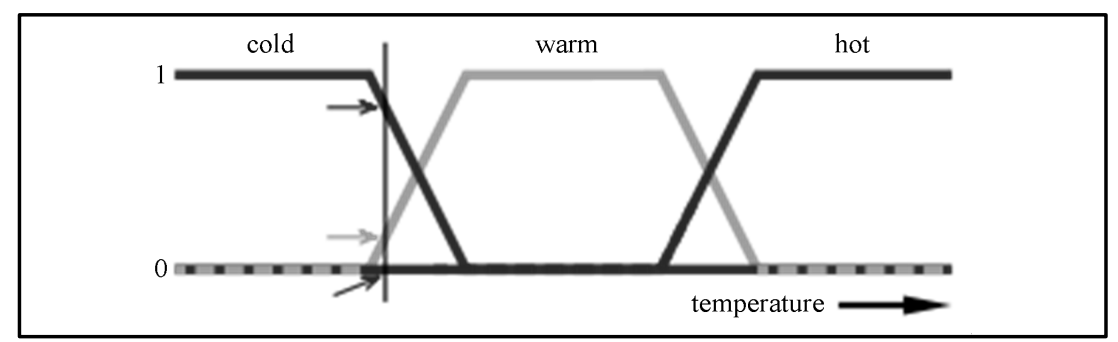

Figure 3. General fuzzy logic system (http://en.wikipedia.org/wiki/Fuzzy_logic).

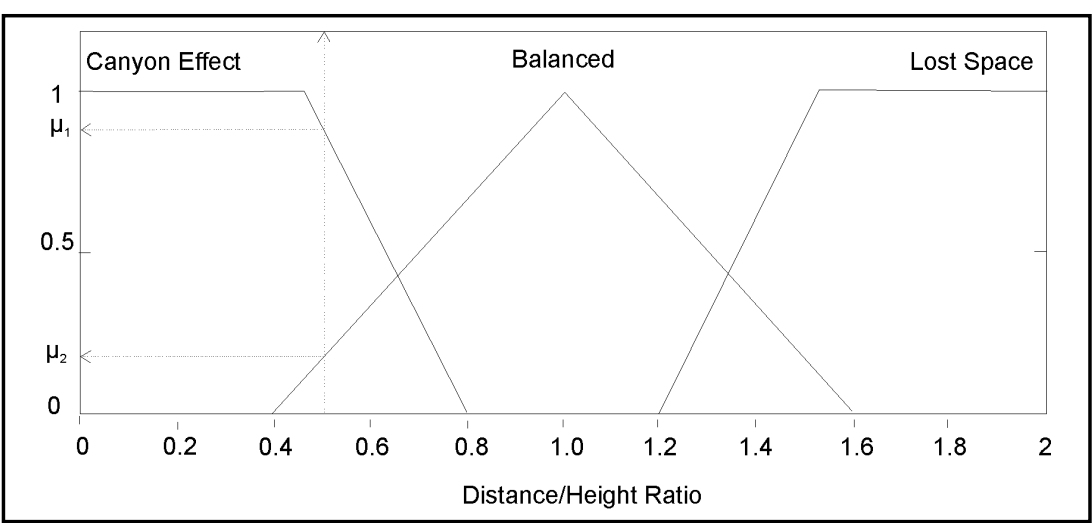

Figure 4. Fuzzy logic inputs and sub-sets (Illustration of fuzzy logic inputs and subsets).

Generally, membership functions must intersect with each other. In the second step, the inputs must be processed with the rules of fuzzy logic, and these rules must be identified by an expert, who demonstrates his experience with the identification of an "if-than" verbal description. For example, Figure 2 shows a set that defines the ratio of distance between buildings (D) and the ratio to building height $(\mathrm{H})$. The ratio $\mathrm{D} / \mathrm{H}$ is one of the components that define the quality of the UI. This set is respectively composed of three sub-sets: canyon effect, balance condition and lost space. The vertical axis of the set $[0,1]$ shows the member grade by getting infinite values while the horizontal axis shows the maximum level that the variable can take. For $0.5 \mathrm{D} / \mathrm{H}$ ratio, respectively for the canyon effect of $\mu 1$, for the state of balance $\mu 2$, it takes two member grades. Which member grade it will take has been determined by the expert in the identification of rule-based fuzzy logic? In the third step, the operation of result set defuzzification has been made. Defuzzification provides a transition from a fuzzy set to a constant number. In this particular study, the centre of maxim has been taken as the defuzzification method, and only one value has been obtained for the solution.

\section{Theories/Arguments behind Modelling}

This study is related to "Urban Interfaces" having the role of interaction and transition between architecture/urban planning, building/city, interior/exterior, private/public. After reading literature the authors classified UI with two components as horizontal and vertical. The horizontal component of urban interface is the composition of building masses, their location according to each other, the exterior spaces having volume among buildings; and the vertical component of urban interface is the totality of series of facades defining exterior spaces and the views included in the vertical section.

\subsection{The Horizontal Component of UI}

The horizontal component of UI is the open areas between buildings. In general in the literature, the space between the masses is called exterior space. However, exterior space is variable in scale and function. According to Bakan and Konuk [51], urban exterior space is an area for urban recreation. On the other hand, Krier [52] has mentioned streets and squares as exterior spaces. Ashihara [53] [54] has explained exterior space as "roofless 
architecture”. And according to Ching [55], urban exterior spaces change in scale from great urban gaps to minor interior courtyards. At this point, the differences between open space and architectural exterior space should be explained. Open space is different in scale from architectural exterior space. "Architectural exterior spaces" are open or half-open places that contain arrangements shaped naturally and/or by the hand of human beings around buildings, between buildings and the relationship of buildings between each other; are dependent on climate and function of the building; meet the necessities of the people like housing, recreation, and provide the opportunity for technical services like car parks as well as children's play parks [48].

\subsection{The Vertical Component of UI}

Discussion about the vertical component of UI as Benjamin [56] has mentioned is a very special architectural field. Façades, the boundaries of exterior space, are the vertical component of UI [46] [47]. UI-formed architectural façades belong to structures and limit the space. In addition, all parts of façades and all views belonging to cross-section lines of space define UI [45]. The difference between the exterior façade and the interface is in addition to the horizontal dimension, all components visible to the eye up to the point bounded by the sky and which provides a sensitive completeness between in and out is in the scope of interface. In addition, UI contains not only two-dimensional façades, but also three-dimensional arrangements that contain the building itself [52]. Façades are the walls that turn exterior to interior and the transition zones that function changes [45] [52] [57]. They are a critical boundary that provides definition to an urban image and the transition limit between two types of space (architectural space and urban space) [45] [52] [58]. Sides are defined on one side as architectural space and on the other side as urban space [41]. Firstly, spaces give the identity of sides of the buildings that sets a symbolic and functional link between in/out [46] [47]. The arrangement of openings, their ratios, and their details provide visual hierarchy on façades. Façade elements other than openings (like supports, columns, buttresses, cantilevers, window boxes, niches, projections, balconies, door steps, first floor levels and showcases, shapes of roofs, solar panels, advertisement boards, and valances) are also sometimes used as elements providing structural durability or as rhythmic elements on the sides, determining the vertical component of the interface [41] [45]-[47] [59]. Those UI components high in quality are shown in Figure 5 and the UI properties high in quality are explained in Table 1 and Table 2.

\section{The Model}

It is possible to discuss the UI phenomena with different paradigms. The determinist paradigms, including a series of pre-admissions with comments and visions in the cause-result cycle, usually needs supporting in explaining concepts with multi-compound concrete-abstract contents like space. As far as science is concerned, positivist and phenomenological paradigms are sufficient. However, it seems compulsory to make new approaches as far as art, architecture and urban design are concerned. Recently, fuzzy logic has been among new scientific paradigms. While judging, people's knowledge depends on their experiences. The psychology of perception and

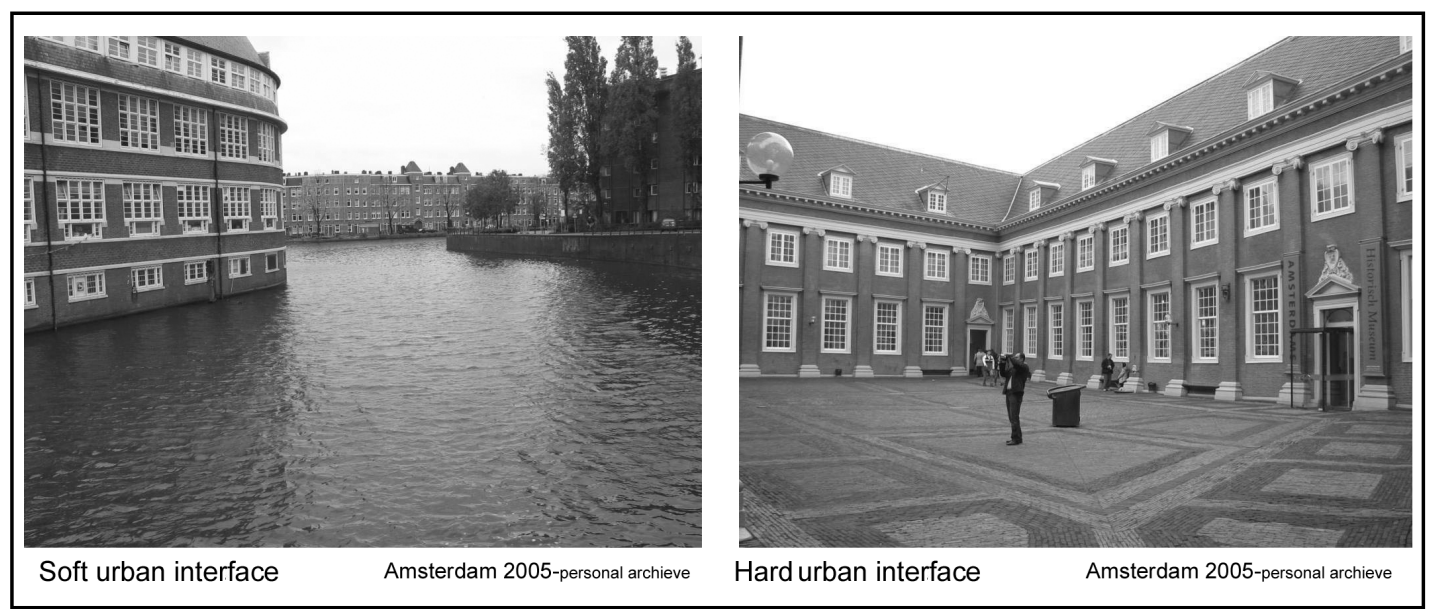

Figure 5. Hard-soft space (personal archive). 
Table 1. Horizontal properties of urban interfaces high in quality.

Component properties of UI high in quality

Horizontal viewing quality

Urban Services The arrangement of pedestrian motor vehicle is very important indicator of UI [51] [60]. Adequate car park parking, playgrounds for children of all ages and properly designed furniture must exist [54] [60] [61].

In a well-qualified UI, a visual richness must be supplied by natural elements like landscape elements, floor paving,

Visual Quality and lighting elements. Trees especially clean the air and give meaning, scale and aesthetics to the environment [53] [62] which should also be maintained with landscape designs that are realistic [63].

A well-qualified UI must contain three-dimensional designs that take site properties seriously, that have been produced as Slope a result of an analysis of topographic data, that regulate differences in altitude and that are in harmony with the rate and direction of inclination [61].

In a well-designed urban interface, microclimatic analyses like climate-dependent orientation, shades that are formed

Climatic Effect by supporting walls of structures or trees, sunlight, wind corridor and the function and landscape design of spaces in the immediate environment of the buildings must be determined [61] [63].

\section{Horizontal sensing quality}

In an UI, series of spaces that are perceived in motion passing from one to another must be displayed in a continuous and themselves [58]. Hierarchy must be in ordered to provide transitions from public to private, from open to closed and from external to internal [41] [64]. Sharp changes from public to private must be avoided [41] [51] [57] [58] [65]-[69].

UI changes depending on whether the perceiver is at vehicle speed or at pedestrian speed. A well-designed UI must

Continuity take the pedestrian as a measure and involve solutions that fit the speed of the pedestrian [58] [60] [70] [71]. In order to define clear paths, continuity should be provided [57] [61] [72]-[74].

An UI must create a sense of closure that enables people to establish control over spaces and is guarantee of security, confidentiality and belonging. While weak closure is the disappearance of images and the loss of direction, strong closure defines areas of territoriality and thus vandalism decreases [7] [54] [64] [67] [71]. Closure is provided by building walls, huge trees or bridges [67] (Figure 6).

In UI, the ratio of the height of a building $(\mathrm{H})$ to the distance between buildings (D) must be 1 or close to 1 [48] [52]Distance/Height [54] [58] [75]. If this ratio is below 1, it causes a sense of imprisonment and claustrophobia; if it is above 1, it does away Ratio with spatial effect and causes lost space [5] [58]. The spatial properties of D/H and the effects of D/H on human perception has been studied extensively [52] [54] (Figure 7).

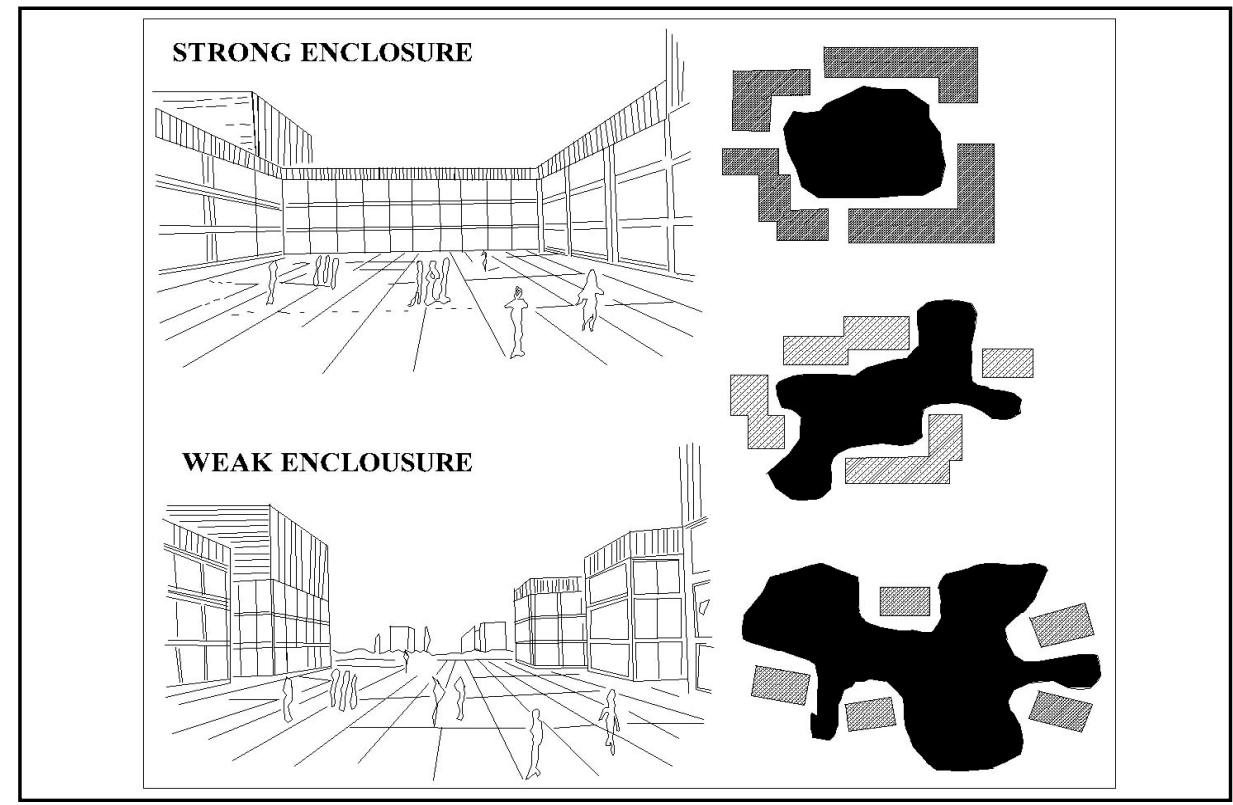

Figure 6. The effects of enclosure [(improved by the help of ([67] pp. 12-13), ([48] p. 60)]. 


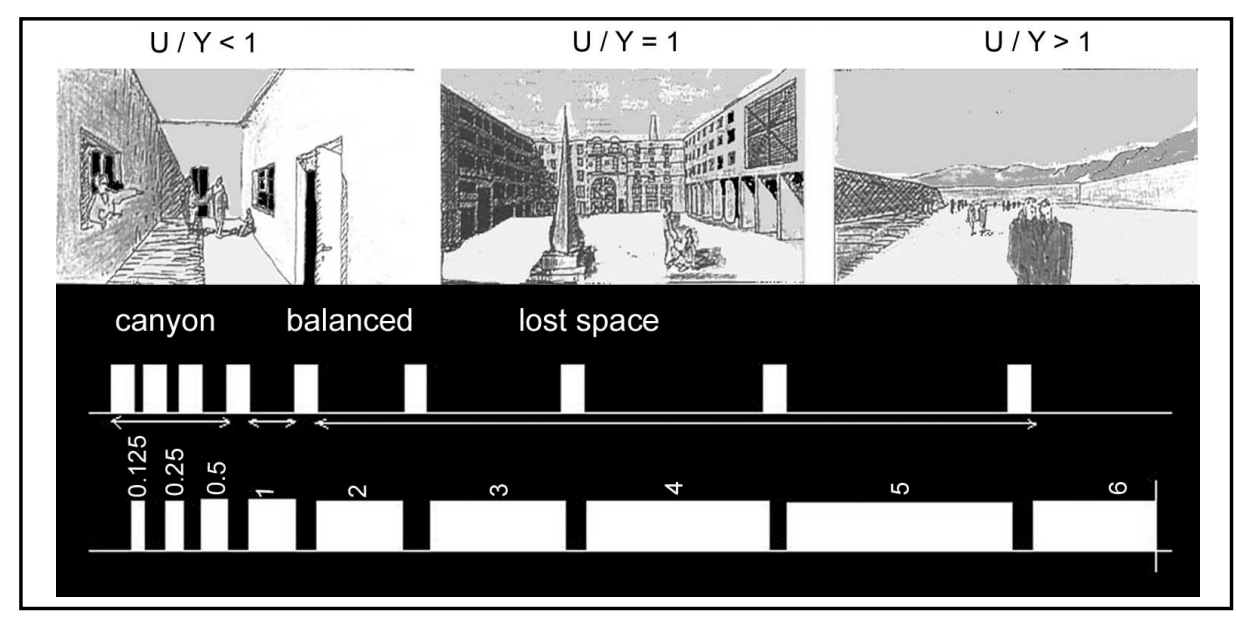

Figure 7. Distance/height ratio [following ([53] p. 43), ([54] pp. 47-48-54), ([52] p. 55).

Table 2. Vertical properties of urban Interfaces high in quality.

\begin{tabular}{c}
\hline Component properties of UI high in quality \\
\hline Vertical viewing quality \\
\hline
\end{tabular}

Height Difference

Variety in height is another factor of UI. Changes in height provide variety and scale. Varying building height and setback and establishing lower scales adjacent to pedestrian areas reduces bulky appearances [7] [70].

Transparency Level interface [58] [70] [76]. It is openings that give the identity of building façades by connecting exterior and interior with symbolic and functional way [41] [45]-[47] [59].

For a well-designed UI, the balance of repetitions and variety must be set. Instead of monotonous façades of buildings that repeat one after another, variety that provides a richness of experience with components like rhythm, difference and surprise elements is preferred [77]. Variety is achieved not only from chaos and complexity by providing a rhythmically meaningful unity in which differences, complexity and repetition are perceived as an independent pattern from each other but also from monotony in which there exists no difference and the existing pattern is repeated excessively [45] [58] [60] [69] [70] [78].

While forming UI, there must be arrangements that seem interesting to pedestrians like opening of ground floors

Ground Level Usage to the space in front of them or shop windows on the ground floor that are lit at night [45] [52] [68] [79]. The use of brand store showcases, certain materials, colors, ornamentation result in people passing and prevents crime [80] (Figure 8).

\section{Vertical sensing quality}

In a well-designed UI, façade analyses that contain plastic harmony determined by horizontal/vertical traces of buildings, solid-void balance, materials used on the façade, decorations, properties of color and architectural details must be carried out [48] [52] [70].

Static space is just like a room in interior space [48]. Courtyards, gardens, squares are stable space that symbolize calmness and relaxation [67]. On the other hand, dynamic space is linear and involves traffic through it. The way

Static-Dynamic Space of motion is not only physical but also visual. Circulation, liveliness and vitality are the properties of dynamic space. Dynamic space is less claustrophobic than static ones (Figure 9).

For a well-designed UI, architectural details that will reduce the scale to pedestrian scale in a vertical component like partitions, indents, projections of units of structures, rises and decreases in the surfaces of the walls, changes

Achieving Scale in height, and the use of eaves, columns and arcades are required [58]. Different façade surfaces extending-removing, pushing-pulling, protruding-intruding from the outside of a building combines into visual richness. The ratio of solid-void balance on the façade as a boundary of UI affects scale [52].

When private and public is separated from each other with a plane, it is called hard UI. "Hard space" in generally formed by buildings [45] [47] [61] [74]. Although hard space has a primary function [47], soft space

Hard-Soft Space plays secondary role in UI [48]. Hard space consists of arranging a row in space. Both natural elements and buildings form soft space. Soft space is a place where climatic effects can be felt, where nature is dominant, and where people relax [47] [74]. 
differences of perception can be added to the model. For UI to be easy and understandable in terms of fuzzy logic, the vertical and horizontal compounds are taken as a fuzzy system. The "Horizontal" and "Vertical" compounds are each divided into two parts as concrete (viewing) and abstract (sensing) qualities. In this model, the "Horizontal Compound Viewing" is a rule-based fuzzy logic system and there are four inputs and one output. The "Horizontal Compound Sensing" is also designed in the same way. The outputs of these two systems have been taken as output for the Horizontal Compound. The vertical compound is also designed as two different systems, "Vertical Compound Viewing" and "Vertical Compound Sensing" and the outputs of these systems have been taken as two outputs for the Vertical Compound. The Horizontal and the Vertical Compounds are taken as the output of UI system (Figure 10). We can explain this system as an instrument of quality determiner that is formed from 16 different parameters depending on expert experience and preferences.

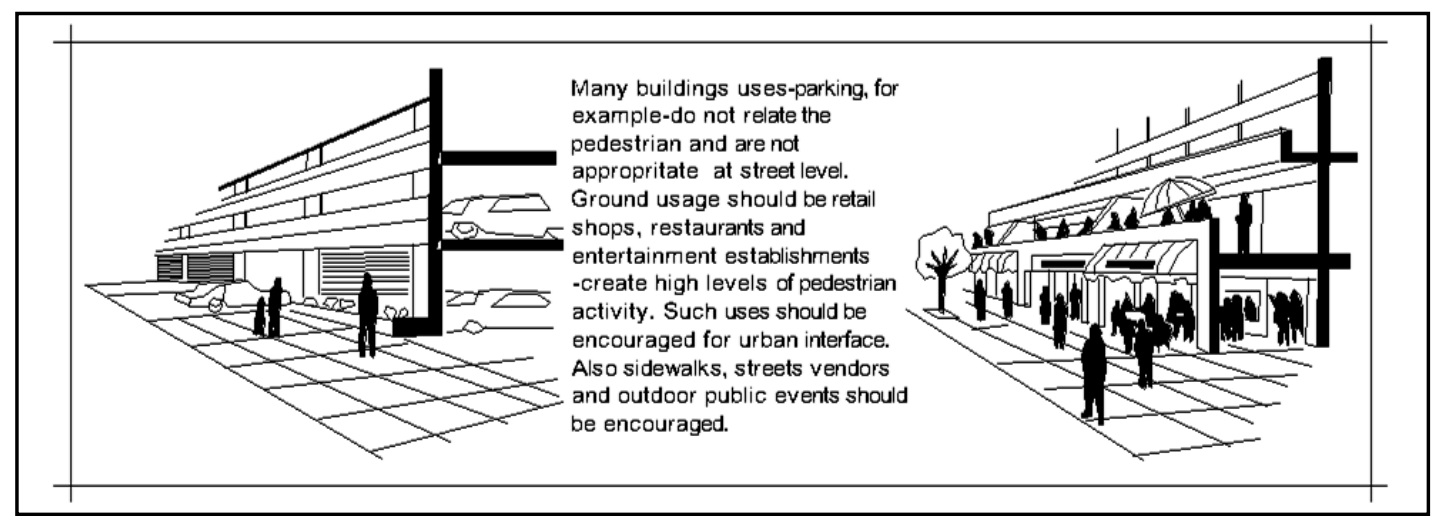

Figure 8. Ground level usage (from [70] p. 25).

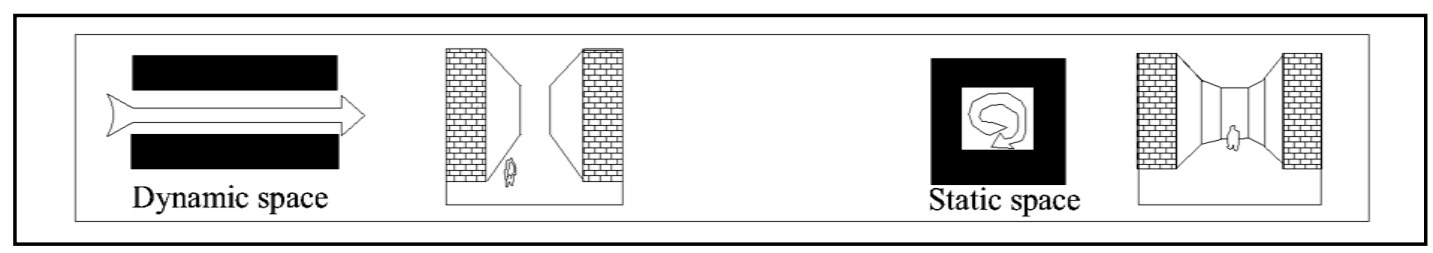

Figure 9. Static-dynamic [improved by ([67] p. 16), ([45] p. 16) and ([48] p. 73)].

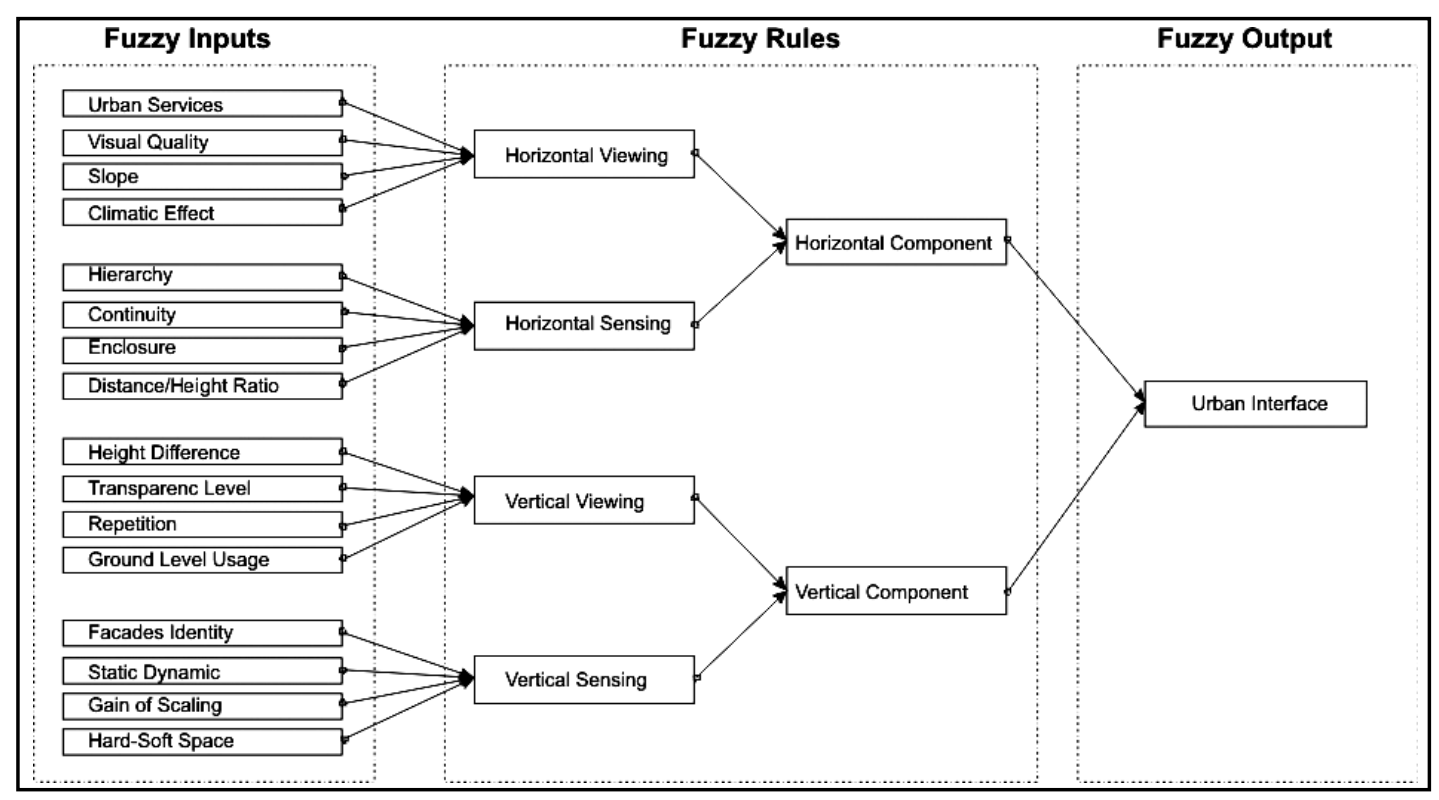

Figure 10. UI fuzzy logic model. 
If we define this system statistically, the number of verbal input variables is sixteen, the number of verbal output variables is seven, the number of rule blocks is seven, the total rule numbers is one hundred and sixtyseven and the number of membership functions used in the model is sixty six. The change of these parameters with different expert's definitions makes different models possible. For example, the Horizontal Viewing quality of UI fuzzy model is shown in Figure 11. The four fuzzy input sets are respectively, Slope, Climatic Effect, Visual Quality and Urban Services. The sub-sets of these sets are given in Figure 11 and Figure 12.

\begin{tabular}{|c|c|c|c|c|c|c|c|c|c|c|c|}
\hline \multicolumn{2}{|c|}{$\begin{array}{l}\text { COMPONENT } \\
\text { TERMINOLOGY }\end{array}$} & \multicolumn{3}{|c|}{ SUB-SETS } & FUZZY & & COMPONENT & \multicolumn{3}{|c|}{ SUB-SETS } & FUZZY \\
\hline \multirow{4}{*}{ 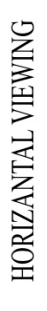 } & SLOPE & Low & fititing & sharp & & $\mathfrak{Z}$ & $\begin{array}{l}\text { TRANSPARENCY } \\
\text { LEVEL }\end{array}$ & insuffucier & & suffucient & \\
\hline & $\begin{array}{l}\text { VISUAL } \\
\text { QUALITY }\end{array}$ & \multicolumn{2}{|c|}{ insuffucient } & suffucient & & \multirow{3}{*}{ 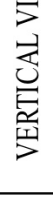 } & REPETITION & \begin{tabular}{|l|l} 
\\
monotony
\end{tabular} & balanced & chaos & \\
\hline & $\begin{array}{l}\text { URBAN } \\
\text { SERVICE }\end{array}$ & Insurffucieint & livable & suffucient & & & $\begin{array}{l}\text { HEIGHT } \\
\text { DIFFERENCE }\end{array}$ & not exist $\quad f$ & fitting & ubbalanced & \\
\hline & \begin{tabular}{|l} 
CLIMATIC \\
EFFECT
\end{tabular} & \multicolumn{2}{|c|}{ negative } & positive & & & $\begin{array}{l}\text { GROUND LEVEL } \\
\text { USAGE }\end{array}$ & \multicolumn{2}{|l|}{ negative } & positive & \\
\hline \multirow{4}{*}{ 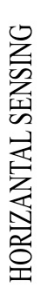 } & HIERARCHY & \multicolumn{2}{|c|}{$\begin{array}{l}\text { Sharp } \\
\text { Transition }\end{array}$} & $\begin{array}{l}\text { Balanced } \\
\text { Transition }\end{array}$ & & \multirow{4}{*}{ 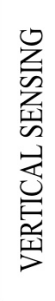 } & $\begin{array}{l}\text { FACADES } \\
\text { IDENTITY }\end{array}$ & poor quality & legible & = high quality & \\
\hline & ENCLOSURE & |nsuffurieient & fitting & sufficieient & & & $\begin{array}{l}\text { ACHIEVING } \\
\text { SCALE }\end{array}$ & \multicolumn{2}{|c|}{ insuffucient } & suffucient & \\
\hline & CONTINUITY & interrupted & balanced & continous & & & $\begin{array}{l}\text { HARD } \\
\text { SOFT SPACE }\end{array}$ & \multicolumn{2}{|l|}{ hard } & soft & \\
\hline & $\begin{array}{l}\text { DISTANCE/ HEIGHT } \\
\text { RATIO }\end{array}$ & \begin{tabular}{|l} 
canyon \\
effect
\end{tabular} & balanced & lost space & & & $\begin{array}{l}\text { STATIC } \\
\text { DYNAMIC SPACE }\end{array}$ & Static & & Dynamic & \\
\hline
\end{tabular}

Figure 11. The extent of evaluating the factors that determine the quality of urban interfaces.

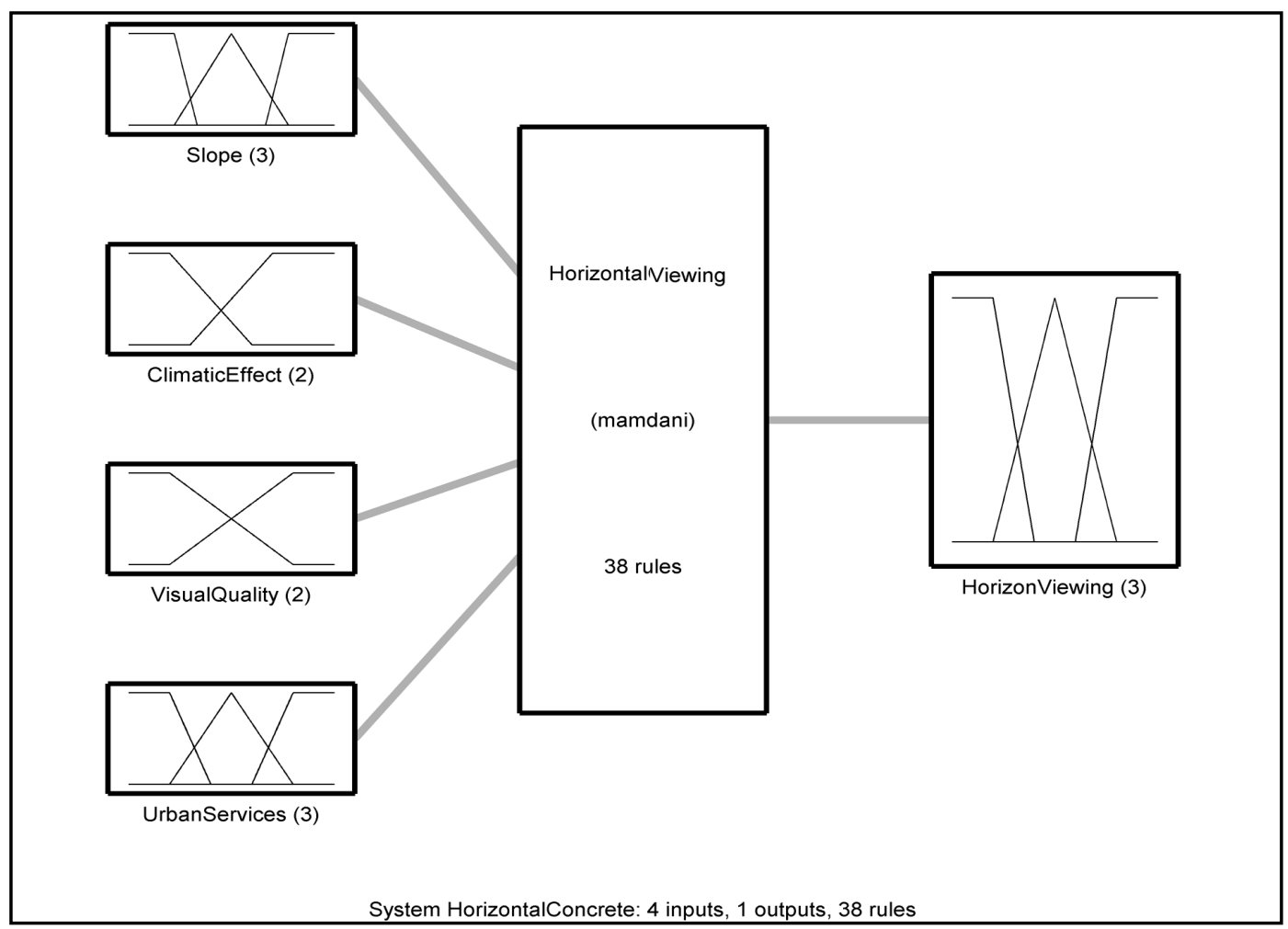

Figure 12. Horizontal viewing fuzzy logic systems. 
The sub-sets of these four fuzzy sets are respectively three, two, two and three. There are thirty eight fuzzy rules written. The Horizontal Sensing quality is similarly modelled. The sub-sets of the Horizontal Sensing quality fuzzy system are Hierarchy, Continuity, Enclosure, and Distance/Height Ratio. The output set of these two, Horizontal Viewing and Horizontal Sensing quality, has been taken as the input of horizontal compound fuzzy set. Being a Horizontal Viewing Quality determiner, the fuzzy input Slope, for example, is composed of 3 sub-sets. These sub-sets are classified in such intervals as low (0 - 15), fitting (10 - 35), and sharp (30 - 45). In Figure 13, membership functions used for the parameters can be seen.

The extent of choosing these intervals is the determined values when there are suitable structure conditions for slope mentioned in the literature. According to this, it is generally difficult to build in areas with a slope of more than $45 \%$, because it is not economical and it makes special designs compulsory. The compounds of the other 16 factors that determine the extent of UI quality are explained in detail in Figure 11. While being formed, the rules for Horizontal Viewing Quality are identified in our model with thirty-eight rules. Of these rules, the rules including the set of slope are as follows:

3rd Rule: IF Slope $=$ low, Visual Quality $=$ insufficient, Urban Services $=$ insufficient, Climatic Effect $=$ negative, THAN, Horizontal Viewing = Low Quality.

8th Rule: IF Slope = low, Visual Quality = insufficient, Urban Services = livable, Climatic Effect = positive, THAN, Horizontal Viewing = Medium Quality.

15th Rule IF Slope = fitting, Visual Quality = insufficient, Urban Services = sufficient, Climatic Effect = negative, THAN, Horizontal Viewing = Low Quality.

18th Rule IF Slope = fitting, Visual Quality = sufficient, Urban Services = sufficient, Climatic Effect = negative, THAN, Horizontal Viewing = High Quality.

33rd Rule IF Slope = sharp, Visual Quality = insufficient, Urban Services = sufficient, Climatic Effect = positive, THAN, Horizontal Viewing = Medium Quality.

Of the thirty-eight rules written in the Horizontal Viewing Quality fuzzy system, some rules that include D/H proportion are as follows:

3rd Rule IF Hierarchy $=$ Sharp Transition, Enclosure $=$ insufficient, Continuity $=$ Balanced, Distance/Height Ratio = Canyon Effect, THAN, Horizontal Sensing= Low Quality.

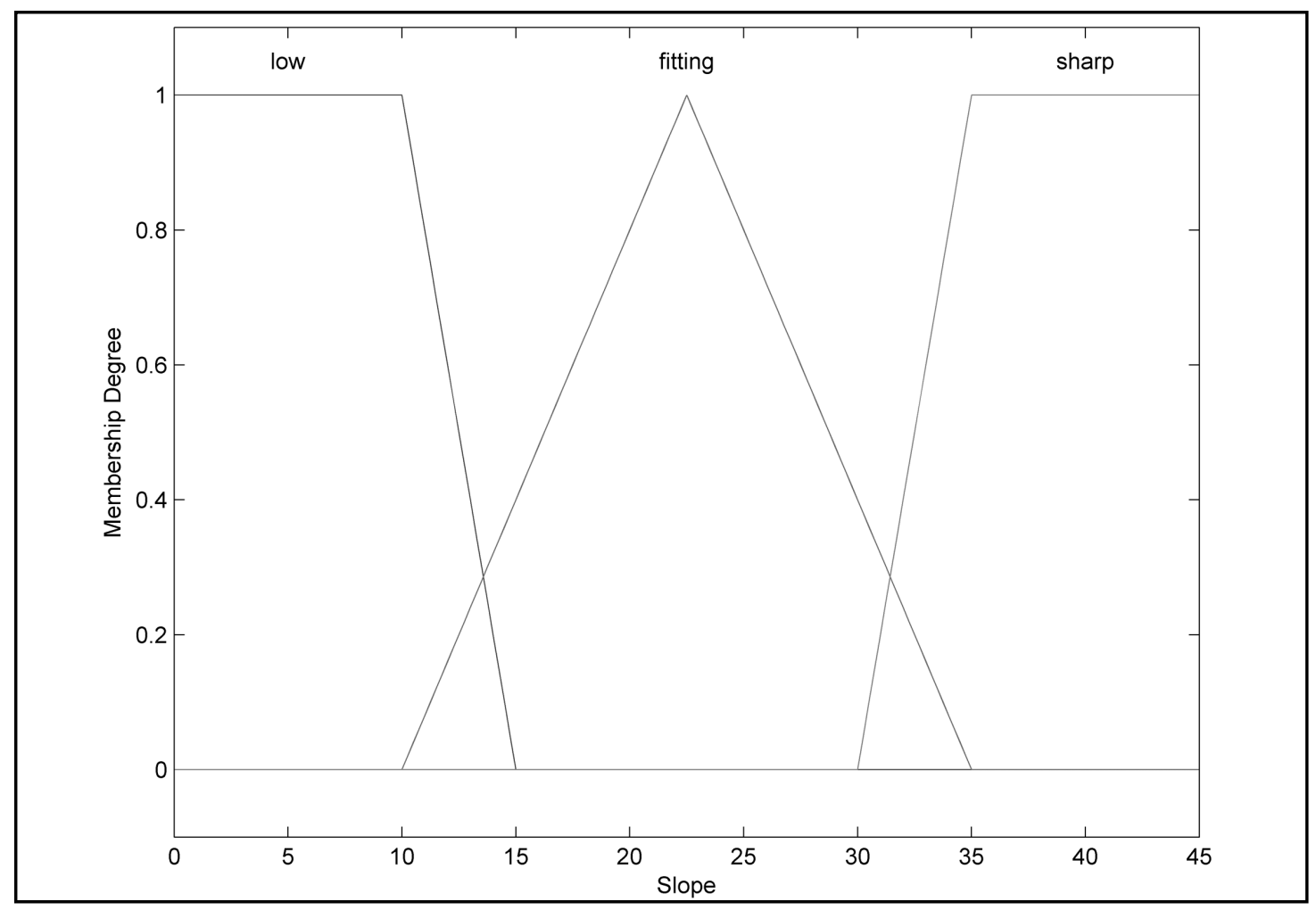

Figure 13. Slope sub-set of horizontal viewing quality. 
9th Rule IF Hierarchy = Balance Transition, Enclosure = fitting, Continuity=Balanced, Distance/Height Ratio

$=$ Canyon Effect, THAN, Horizontal Sensing = Medium Quality.

19th Rule IF Hierarchy = Sharp Transition, Enclosure = insufficient, Continuity = Balanced, Distance/Height Ratio $=$ Balanced, THAN, Horizontal Sensing $=$ Medium Quality .

38th Rule IF Hierarchy = Balanced Transition, Enclosure = sufficient, Continuity $=$ Balanced, Distance/ Height Ratio = Lost Space, THAN, Horizontal Sensing = High Quality .

Similar rules have been written for the formulation for the qualities of Horizontal Viewing, Horizontal Sensing, Vertical Viewing and Vertical Sensing. All inputs and outputs of the UI fuzzy model, 16 different inputs formed by expert experiences and predictions are shown in Figure 13. The model, which we have formed according to the input values, accounts for a UI quality of $25 \%$ low and $75 \%$ high. The model formed will account for different UI values for different input values.

\section{Conclusions}

This work investigates a soft-ware system designed to enable architects and/or urban designer to engage design better physical environment. The concept of UI is the source and the only indispensable element of an architectural structure. However architectural and urban space cannot be defined with accurate boundaries in structures, the design of space is realized heuristically through professional knowledge and experiences. To create a mathematical model of the space will be providing great advantages in analyzing if the design includes the required spatial limits and configuration independent from the designers experiences and instincts.

In this article, a mathematical analyzing model based on fuzzy inference system and supported by fuzzy logic is being presented through examples, and the compensations this model is providing through the design process is being highlighted. Someone interested in UI may make comments about different case study area by using this model and can create his or her own model. Other experts in the same field may use similar way shown in this study to make uncertain values the certain. Space and urban space design should be handled by a conceptual approach rather than a positivist approach.

In this study, the concept of Urban Interface has been modelled using a fuzzy logic method. In addition to abstract parameters, concrete parameters have also been added to the model. The predictions and experiences of a designer are represented in the model, which has been designed to behave like an expert person. Therefore, it has been shown that the definition of "expert system" can be added to architectural software.

Lastly, a model that can give a fuzzy logic system for determining the quality of Urban Interface with sixteen parameters has been presented to the scientific field. We may summarize the result of this study as below:

- The concept of uncertain UI has horizontal and vertical components in urban design field.

- Horizontal components consist of the positioning of buildings in relationship to one other, the design of the buildings and their spaces including the volumes between buildings.

- Vertical components are taken as flexible and fluent environments that are made up of architectural facades that delimit outer spaces.

- The concept of uncertain UI is defined by 16 parameter expression in a way that concept become certain. In other words, UI is tried to be concrete with the software. Although the model makes the concept clear to everyone, it should not be forgotten that it is an expert system.

- UI by fuzzy logic give an opportunity to share easily the concrete knowledge between the experts and this expert system also shows a new way to the one who would like to learn about UI.

- The model provides the experts that a medium for concrete sharing about the UI, it also provides the definition to the one not studying in this special area.

- Someone interested in UI may make comments about different case study area by using this model and can create his or her own model.

- Other experts in the same field may use similar way shown in this study to make uncertain values the certain.

\section{References}

[1] Campbell, H. (2003) Interface. Planning Theory \& Practice, 4, 205-206. http://dx.doi.org/10.1080/14649350307981

[2] Kelbaugh, D. (1997) Common Place: Toward Neighborhood \& Regional Design. University of Washington Press, Seattle.

[3] Calthorpe, P. (1994) The New American Metropolis: Ecology, Community \& American Dream. Princeton Press, New 
York.

[4] Duany, A. and Plater-Zyberk, E. (1992) Towns \& Town-Making Principles. Harvard University Graduate School of Design, Cambridge.

[5] Moughtin, C. (1992) Urban Design-Street and Square. Butterworth Architecture, England.

[6] Moule, E. and Polyzoides, S. (1994) The Street, the Block and the Building in the New Urbanism: Toward Architecture of Community. McGraw-Hill, New York.

[7] Kartz, P. (1994) The New Urbanism: Toward an Architecture of Community. Mc Graw-Hill, Inc. New York.

[8] Radeloff, V.C., Hammer, R.B., Stewart, S.I., Fried, J.S., Holcomb, S.S. and McKeefry, J.F. (2005) The Wildland-Urban Interface in the United States. Ecological Applications, 15,799-805. http://dx.doi.org/10.1890/04-1413

[9] Ewerd, A., (1993) The Wildland-Urban Interface: Introduction and Overview. Journal of Leisure Research, 25, 1.

[10] Ewerd, A., Chavez, D. and Magill, A. (1993) Culture, Conflict and Communication in the Wildland-Urban Interface. Westview Press, Oxford.

[11] Alavalapati, J., Carter, D. and Newman, D. (2005) Wildland-Urban Interface: Challenges and Oppurtunities. Forest Policy and Economics, 7, 705-708. http://dx.doi.org/10.1016/j.forpol.2005.03.001

[12] Westphal, J. (2001) Managing Agricultural Resources At The Urban-Rural Interface: A Case Study of the Old Mission Peninsula. Landscape and Urban Planning, 5, 13-24. http://dx.doi.org/10.1016/S0169-2046(01)00185-2

[13] Vince, S.W., Duryea, M.L., Macie, E.A., Hermansen, L.A. (2005) Forests at the Wildland-Urban Interface: Conservation and Management. CRC Press LLC, Boca Raton, 1-293.

[14] Nicks, S. (2003) Designing The Interface: The Role of Urban Design In Reconstructing Apartheid Villages, Towns and Cities. Urban Design International, 8, 179-205. http://dx.doi.org/10.1057/palgrave.udi.9000103

[15] Madaleno, I.M. and Gurovich, A. (2004) Urban Versus Rural No Longer Matches Reality. Cities, 21, 513-526. http://dx.doi.org/10.1016/j.cities.2004.08.001

[16] Boren, J., Engle, D. and Master, R. (1997) Vegetation Cover Type and Avian Species Changes on Landscapes within a Wildland -Urban Interface. Ecological Modeling, 3, 251-266. http://dx.doi.org/10.1016/S0304-3800(97)00108-7

[17] Hovardas, T. and Stamou, G. (2006) Structural and Narrative Reconstruction of Rural Residents' Representations of Nature, Wildlife and Landscape. Biodiverstiy and Conservation, 15, 1745-1770. http://dx.doi.org/10.1007/s10531-004-5021-1

[18] Nunan, F. (2001) Rural-Urban Interactions. Third World Planning Review, 23, 387-403.

[19] Bell, K., Irwin, E. (2002) Spatially explicit Micro-Level Modelling of Land Use Change at the Rural-Urban Interface. Agricultural Economics, 27, 217-232. http://dx.doi.org/10.1016/S0169-5150(02)00079-8

[20] Moore, J. (2006) Implement Interface Architecture. Rice University, Houston.

[21] Davis, J. (1990) The Wildland-Urban Interface: Paradise or Battleground? Journal of Forestry, 88, 26-31.

[22] Bradley, G. (1984) Land Use and Forest Resources in a Changing Environment. The Urban/Forest Interface. University of Washington Press, Seattle.

[23] Kelly, J. (1980) Outdoor Recreation Participation: A Comparative Analysis. Leisure Science, 3, 129-154. http://dx.doi.org/10.1080/01490408009512931

[24] Smaldone, D., Harris, C. and Sanyal, N. (2006) An Exploration of Place as a Process. Journal of Environmental Psychology, 25, 397-414. http://dx.doi.org/10.1016/j.jenvp.2005.12.003

[25] Sasidharan, V. (2002) Special Issue Introduction: Understanding Recreation and Environment within the Context of Culture. Leisure Sciences, 24, 1-11. http://dx.doi.org/10.1080/01490400252772809

[26] Batty, M. and Longley, P.A. (1994) Fractal Cities. Academic Press Inc., Waltham, 228-229.

[27] Halkatti, M., Purushothaman, S. and Brook, R. (2003) Peri-Urban Planning, Participatory Action Planning in the PeriUrban Interface. Environment \& Urbanization, 15, 149-158.

[28] Carr, D.S. and Williams, D.R. (1993) Understanding the Role of Ethnicity in Outdoor Recreation Experiences. Journal of Leisure Research, 25, 22-38.

[29] Tacoli, C. (1999) Understanding the Opportunities and Constraints for Low-Income Groups in the Peri-Urban Interface: The Contribution of Livelihood Framework. DPU Research Project, London.

[30] Stewart, W.P., Liebert, D. and Larkin, K.W. (2004) Community Identities as Visions for Landscape Change. Landscape and Urban Planning, 69, 315-334. http://dx.doi.org/10.1016/j.landurbplan.2003.07.005

[31] Gallent, N., Bianconi, M. and Andersson, J. (2006) Planning on the Edge: England's Rural-Urban Fringe and the Spatial-Planning Agenda. Environment and Planning B: Planning and Design, 33, 457-476. 
http://dx.doi.org/10.1068/b31171

[32] Winter, G. and Fried, J. (2000) Homeowner Perspectives on Fire Hazard, Responsibility and Management Strategies at the Wildland-Urban Interface. Society and Natural Resources, 13, 33-49. http://dx.doi.org/10.1080/089419200279225

[33] Russell, W. and McBride, J. (2003) Landscape Scale Vegetation-Type Conversion and Fire Hazard in the San Francisco Bay Area Open Spaces. Landscape and Urban Planning, 64, 201-208. http://dx.doi.org/10.1016/S0169-2046(02)00233-5

[34] Lowden, T. and Francis, D. (1998) Branching Out into the Interface. Fire Chief, 42, 52.

[35] Platt, R.V. (2006) A Model of Exurban Land-Use Change and Wildfire Mitigation. Environment and Planning B: Planning and Design, 33, 749-765. http://dx.doi.org/10.1068/b32073

[36] Kalabokidis, K. and Omi, N. (1998) Reduction of Fire Hazard through Thinning/Residue Disposal in the Urban Interface. Wildland Fire, 8, 29-35. http://dx.doi.org/10.1071/WF9980029

[37] Carree, Y., Schnepf, C. and Colt, W.M. (1998) Landscaping for Wildlife Prevention: İdaho Forest. Wildlife and Range Experiment Station, Moscow.

[38] Cole, D. (1987) Effects of Three Seasons of Experimental Trampling on Five Montage Forest Communities and a Grassland in Western Montana. Biological Conservation, 40, 2/244.

[39] Cortner, H.J. (1991) Interface Policy Offers and Challenges: USDA Forest Service Strategies and Constraints. Journal of Forestry, 89, 31-34.

[40] Cortner, H.P. and Taylor, J.G. (1990) Fire Hazards at the Urban-Wildland Interface: What the Public Expects. Environmental Management, 14, 57-62. http://dx.doi.org/10.1007/BF02394019

[41] Gehl, J. (1977) The Interface between Public \& Private Territories in Residential Areas. Department of Arch and Building, Melbourne University, Australia.

[42] Gorden, E. (2003) Urban Interfaces: Building Images in the 20th Century American City. University of Southern California, Los Angeles.

[43] Hospers, G. (2003) Jane Jacops: Visionary of the Vital City. Planning Theory \& Practice, 4, 207-212.

[44] Leo, C. and Anderson, K. (2006) Being Realistic About Urban Growth. Journal of Urban Affair, 28, 169-189. http://dx.doi.org/10.1111/j.0735-2166.2006.00266.x

[45] Özaydın, G. (1993) A Systematical Approach Comprehensing Urban Design to Arrangements of Urban Interface in the Historical Area/Kentsel Tasarım Kapsamında Tarihi Kentsel Mekanlarda Arayüzleri Düzenlenmesine Sistemli Bir Yaklaşım. PhD Dissertation, Mimar Sinan University, İstanbul.

[46] Özyörük, İ. (1995) The Interface of Architectural Built Form and Urban Outdoor Space. M.S. Thesis, Middle East Technical University, Ankara.

[47] Köknar, B. (2001) An Analysis on Integration of Spatial Interfaces with City and Life. M.S. Thesis, İstanbul Technical University, İstanbul.

[48] Bala, A.H. (2003) Analytical Frame towards the Arrangement of Urban Interfaces in Residential Areas. PhD Dissertation, Selcuk University, Konya.

[49] Joedicke, J. (1985) Space and Form in Architecture. Karl Kramer Verlag, Stuttgard.

[50] Zadeh, L.A. (1965) Fuzzy Sets. Information Control, 8, 338-353. http://dx.doi.org/10.1016/S0019-9958(65)90241-X

[51] Bakan, K. and Konuk, G. (1987) Türkiye'de Kentsel Dış Mekanların Düzenlenmesi/The Arrangement of Urban Exterior Space in Turkey. TÜBİTAK Yapı Araştırma Enstitüsü Yayınları, Ankara.

[52] Krier, K. (1984) Urban Space. Rizzoli International Publication, New York

[53] Ashihara, Y. (1970) Exterior Design in Architecture. Van Nostrand Reinhold Company, New York.

[54] Ashihara, Y. (1983) The Aesthetic Townscape. MIT Press, Cambridge.

[55] Ching, F.D.K. (1996) Architecture; Form, Space \& Order. Van Nostrand Reinhold, New York.

[56] Benjamin, A. (2006) Surface Effect: Borromini, Semper, Loos. The Journal of Architecture, 11, 1-36. http://dx.doi.org/10.1080/13602360600636099

[57] Lynch, K. (1986) The Image of the City. MIT Press, Cambridge.

[58] Alexander, C., Ishikawa, S. and Silverstein, M. (1977) A Pattern Language, Volume 2. Oxford University Press, New York.

[59] Colom, A. (1996) The Process of Design: A Tool in the Exploration \& Understanding of Place. Master of Science in Architectural Studies, Graduate School of Natural and Applied Sciences, MIT, Cambridge.

[60] Rapoport, A. (1977) Human Aspects of Urban Form: Towards a Man-Environment Approach to Urban Form and De- 
sign. Paragon Press Ltd., Oxford.

[61] Özbay, E. (1997) Principles for Arrangement of Spaces between Building in Residential Areas. M.S. Thesis, Mimar Sinan University, İstanbul.

[62] Sitte, C. (1965) City Planning According to Artistic Principles. Random House, New York.

[63] Evyapan, G. and Tokol, A. (2000) Landscape Design Lectures. METU Faculty of Architecture Press, Ankara.

[64] Schulz, N.C. (1971) Existence Space \& Architecture. Studio Vista, Praeger Publishers Inc., London.

[65] Günay, B. (1999) Urban Design Is a Public Policy. Middle East Faculty of Architecture Press, Ankara.

[66] Newman, O. (1972) Defensible Spaces, People \& Design in Violent City. Architectural Press, London.

[67] GLC Study (1978) An Introduction to Housing Layout. The Architectural Press, New York.

[68] Önür, S. (1992) Architectural Experiences and Experiments in the Public Sphere. PhD Dissertation, Middle East Technical University, Ankara.

[69] Alexander, C. (1981) Timeless Way of Building. Oxford University Press, New York.

[70] Shirvani, H. (1985) The Urban Design Process. Van Nostrand Reinhold Company, New York.

[71] Lang, J. (1994) Urban Design; The American Experience. Van Nostrand Reinhold, New York.

[72] Rapoport, A. and Kontor, R.E. (1976) Complexity \& Ambiguity in Environmental Design. AIP Journal, 33, $106-111$.

[73] Lozano, O.E. (1990) Community Design \& Culture of Cities. The Crossroad and the Wall, Cambridge University Press, Cambridge.

[74] Trancik, R. (1986) Finding Lost Space; Theories of Urban Design. Van Nostrand Reinhold Company, New York.

[75] Ford, L.R. (2000) The Spaces between Buildings. Johns Hopkins University Press, Baltimore.

[76] Whyte, W. (1980) The Social Life of Small Urban Spaces. Conservation Foundation, Washington DC.

[77] Rubenstein, H.M. (1989) Pedestrian Malls. Street, Spaces and Urban Spaces. John Wiley \& Sons, New York.

[78] Cullen, G. (1975) Townscape. Van Nostrand Reinhold Company, New York.

[79] Bacon, E. (1976) Design of Cities. Penguin Book, New York.

[80] Jacobs, J. (1984) The Death \& Life of Great American Cities. Penguin Books Ltd., New York. 